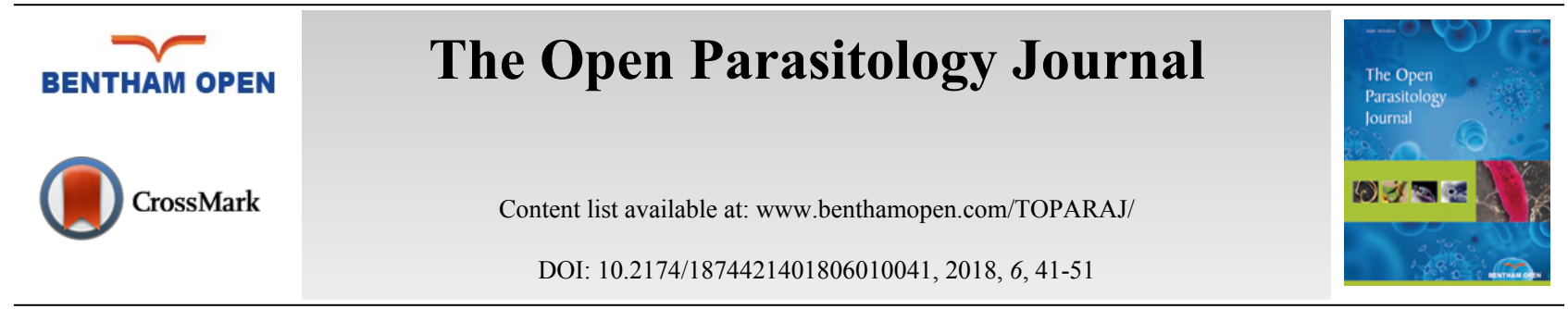

RESEARCH ARTICLE

\title{
Effects of Achyranthes aspera Extracts on the Survival and Midgut Histo-architecture of Aedes aegypti L. Early IV Instars
}

\author{
Aarti Sharma ${ }^{1}$, Sarita Kumar $^{2, *}$ and Pushplata Tripathi ${ }^{1}$ \\ ${ }^{1}$ School of Sciences, Indira Gandhi National Open University, Maidan Garhi, New Delhi 110068, India \\ ${ }^{2}$ Department of Zoology, Acharya Narendra Dev College, University of Delhi, Kalka Ji, India
}

Received: May 3, 2018

Revised: August 13, 2018

Accepted: August 28, 2018

\begin{abstract}
:
Background:

Aedes aegypti L.; one of the most important insect vectors in the world; transmits several diseases of concern; Zika, yellow fever, Chikungunya, dengue and dengue haemorrhagic fever. Despite multifarious problems on humans, non-targets and environment; caused by synthetic chemical insecticides; these are still the prime and preferred control measures against dengue vector. Alternative control strategies using eco-friendly and bio-degradable plant products are being explored.
\end{abstract}

\section{Objective:}

The present study investigates the toxic potential of the hexane extract of the leaf and stem of Achyranthes aspera against Ae. aegypti.

\section{Methods:}

The larvicidal potential of extracts was evaluated against dengue larvae as per WHO protocol. Subsequent concentration and timedependent studies assessed their effects on the larval midgut histo-architecture using microtomy techniques.

\section{Results:}

Larvicidal bioassays with $A$. aspera extracts revealed their appreciable larvicidal potential. Hexane extract of the leaf resulted in respective $\mathrm{LC}_{30}, \mathrm{LC}_{50}$ and $\mathrm{LC}_{90}$ values of 67,83 and $140 \mathrm{ppm}$ while exposure to hexane extract of the stem showed respective values of 55, 68 and $115 \mathrm{ppm}$. Extract-exposed larvae at various lethal levels exhibited significant damage, shrinkage, distortion and vacuolization of gut tissues and peritrophic membrane. The disintegration of epithelial cells and cytoplasmic organelles evidenced stomach poison potential of the extracts. The extent of toxicity and damage was concentration and time-dependent; the stem extract imparted more deleterious effects as compared to the leaf extract.

\section{Conclusion:}

Present findings suggest the utilization of $A$. aspera as an alternate control strategy against Ae. aegypti; though further studies against non-targets are needed to ascertain its use in the fields.

Keywords: Achyranthes aspera, Aedes aegypti, Histological architecture, Larvicidal, Midgut, Stomach poison.

\section{Introduction}

Aedes aegypti L. is a worldwide disease vector, transmitting a number of diseases; dengue, Chikungunya, dengue hemorrhagic fever, yellow fever and Zika. The mosquito is prevalent in almost whole tropical and subtropical area

\footnotetext{
* Address correspondence to the author at the Department of Zoology, Acharya Narendra Dev College, University of Delhi, Kalka Ji, India;
} Tel: +919810309912; E-mail: saritakumar@andc.du.ac.in 
and many other parts of the world. World Health Organization has recorded almost 30-fold increase in the dengue incidence since last 50 years causing health risks to almost half of the world population. Over 100 endemic countries have been identified where approximately 50-100 million infections are estimated to occur annually [1]. In India, Union health ministry recorded a total of 99,913 dengue and 27,553 Chikungunya cases in 2015. The number alarmingly increased to 1,29,166 and 64,057 in 2016 taking a total of 465 human lives [2]. In 2017, the dengue cases were further rose by 1.21-fold and a high mortality rate was observed, maximum since 2010 [3]. The increasing number of reported cases transmitted by Ae. aegypti year after year has made this mosquito one of the most serious disease vectors. As of now, no operative vaccine has been formulated which can save people from periodic recurrent outbreaks of dengue fever and dengue hemorrhagic fever [4].

Management of mosquitoes has attracted researchers' interests since long in order to keep the mosquito-borne diseases under check and to provide a safe environment. Primarily, insecticides, mainly organic in origin; organochlorides, organophosphates, carbamates and pyrethroids; have been used for vector control. However, these mosquito control strategies have caused the development of insecticide resistance and led to environmental contamination due to continued accumulation of the slowly and non-degradable toxic compounds [5]. In recent years, application of many of these former synthetic insecticides has been restricted in mosquito control programme on a global scale due to high cost, toxic effects on non-target populations, harm to human health, non-biodegradability, residual properties, a higher rate of biological magnification through the ecosystem, and increasing insecticide resistance. The dire need to look for alternate approaches encouraged researchers to explore the botanicals under biological control programme and enter the field of using botanical insecticides as a simple, safe, cost-effective, biodegradable, eco-friendly and sustainable method of mosquito control.

Floral diversity serves as a natural source of countless compounds that are recognized to encompass mosquito larvicidal agents, which may act against mosquitoes as a synergist in combination with toxicants or independently. Different phytochemicals may possess a different mode of action according to their specific properties and may possess the potential of being general toxicants against various life stages of mosquitoes, whereas others may restrict growth and development, cause reproductive disadvantage or even produce olfactory stimuli and act as attractants/repellents [6, 7]. Mosquito control at the larval stage of development with phytochemicals isolated from different parts of the plant; leaves, stems, barks and roots; is one of the desirable, environment-friendly and affordable approaches today [8]. Consequently, the natural products of plant origin exhibiting insecticidal properties have been explored in recent years for control and management of a variety of insect pests and vectors; and are considered as effective, preferred and sustainable alternatives for mosquito control. Nevertheless, botanicals, regardless of being the focus of research nowadays, have not been investigated extensively for their adverse and systemic effects on physiological systems leading to histolysis of gut tissues, and thus alteration in nutrition impacting growth and development of mosquito vectors. Leaf extracts prepared from Schinus terebinthifolius have been reported to cause damage to the midgut of Ae. aegypti larvae, interfering with survival and development [9]. Morphological alterations in the midgut of third instar Ae. aegypti has been reported by Costa et al. [10] after exposure to a methanolic extract of Annona coriacea (Magnoliales: Annonaceae). Likewise, Gusmão et al. [11] evidenced the modification in the peritrophic matrix and extensive damage of the midgut epithelium of Ae. aegypti larvae after $4 \mathrm{~h}$ of feeding with $150 \mu \mathrm{g} / \mathrm{mL}$ of Derris urucu extract. The crude extracts of Carum copticum caused cytopathological alterations in the midgut epithelium of Culex pipiens larvae. It has been observed that during metamorphosis, a comprehensive transformation of midgut cells takes place in Ae. aegypti larvae and new cells are formed replacing old ones [12]. Consequently, the lethal effects of phytochemicals on the midgut tissues may affect growth and development adversely [13, 14].

Present investigations were performed to explore Achyranthes aspera (Amaranthaceae) for its lethal effects on the survival and gut histo-architecture of Ae. aegypti. A. aspera is an invasive weed, distributed throughout India, tropical Asia and other parts of the world. It has been reported as the most widespread herb in Shivbari sacred grove of Himachal Pradesh, India and an exotic medicinal plant of district Lalitpur, Uttar Pradesh, India. The plant has been reported to possess larvicidal activity, pupicidal activity and pronounced insect molting hormonal activity against mosquito larvae [15].

The leaves and stems of $A$. aspera were extracted in hexane and their effect was assessed on the survival and modifications in the histological architecture of early fourth instars of Ae. aegypti. The extent of gut damage was evaluated at different concentrations; sub-lethal $\left(\mathrm{LC}_{30}\right)$, median-lethal $\left(\mathrm{LC}_{50}\right)$ and lethal $\left(\mathrm{LC}_{90}\right)$; and different exposure durations $(6 \mathrm{~h}, 12 \mathrm{~h}$ and $24 \mathrm{~h})$. 


\section{MATERIALS AND METHODS}

\subsection{Plant Collection}

Fresh, young and healthy leaves and stems of A. aspera were collected from a native area of New Delhi, India. The plant was taxonomically identified with the help of Dr. Arun K. Pandey, Professor, Department of Botany, University of Delhi. The voucher specimen of the weed was deposited in the University of Delhi Herbarium (DUH) with accession no. 14376 .

\subsection{Preparation of Achyranthes aspera Extracts}

The extracts of $A$. aspera were prepared by maceration method in which different parts, i.e. leaves and stems were shade-dried and ground into fine powder using an electric blender. The $250 \mathrm{~g}$ of powdered leaf and stem were separately extracted with $1000 \mathrm{~mL}$ of hexane and left undisturbed for 5 to 7 days. The hexane was selected as solvent of extraction based on our previous studies [16] which demonstrated the larvicidal efficacy of hexane extracts as compared to ethanolic extracts. The hexane extracts, thus obtained, were concentrated using a vacuum evaporator (Buchi Type) below their boiling point $\left(60^{\circ} \mathrm{C}\right)$ under low pressure and stored in a refrigerator at $4^{\circ} \mathrm{C}$ as the stock solution using ethanol as solvent. Different concentrations were prepared for the bioassay using ethanol as a solvent and tested against larvae within a week. The chemical insecticide of plant origin; Permethrin (Amico), with efficient larvicidal activity; was taken as a positive control [17].

\subsection{Rearing of Aedes aegypti Mosquitoes}

The present investigations employed the early fourth instars of dengue fever mosquito, Ae. aegypti. The eggs of Ae. aegypti were obtained from the renowned and established Vector Borne Diseases Laboratory, International Centre for Genetic Engineering and Biotechnology (ICGEB), New Delhi, India. Eggs and larvae of Ae. aegypti were reared in enamel trays filled with dechlorinated tap water. The colony was maintained in Insect Pest and Vector Laboratory, Acharya Narendra Dev College, University of Delhi, New Delhi, India under controlled conditions of temperature $28 \pm$ $1{ }^{\circ} \mathrm{C}, 80 \pm 5 \%$ relative humidity and $14 \mathrm{~L}: 10 \mathrm{D}$ photoperiod [16]. Adult mosquitoes were raised in cloth cages and water-soaked deseeded split raisins were provided as a source of the food, primarily for the male adults. Periodic blood meals required for the egg maturation were provided to the female adults by keeping a restrained albino rat inside adult cloth cage for 1-2 $\mathrm{h}$ after two days of their emergence. The eggs were collected in an enamel bowl $(6 \mathrm{~cm}$ diameter $)$ filled with de-chlorinated tap water and lined with Whatman filter paper strips. The filter strips and water laid with eggs were transferred to a tray $(25 \mathrm{~cm} \times 30 \mathrm{~cm} \times 5 \mathrm{~cm})$ containing de-chlorinated tap water for hatching which was changed every alternate day to prevent formation of scum and hatched larvae were provided a pinch of food powder (dog biscuits and live yeast powder, $3: 1 \mathrm{w} / \mathrm{w}$ ) daily. The pupae formed were separated into an enamel bowl and kept inside the cloth cages for adult emergence.

\subsection{Effect of Achyranthes aspera Extracts on the Survival of Aedes aegypti Larvae}

The larvicidal bioassay was performed at $28 \pm 1{ }^{\circ} \mathrm{C}$ on Ae. aegypti larvae in agreement with the procedure described by WHO with slight modifications [18]. Three replicates were conducted simultaneously for each graded concentration ranging from $20 \mathrm{ppm}$ to $1000 \mathrm{ppm}$ along with control. Controls were exposed to the solvent, that is, ethanol alone. The $\mathrm{LC}_{30}, \mathrm{LC}_{50}$ and $\mathrm{LC}_{90}$ concentrations were analyzed by the probit method using SPSS, Statistical Software Package (Version: 19.0). The lethal concentrations causing $50 \%$ mortality $\left(\mathrm{LC}_{50}\right)$ and $90 \%$ mortality $\left(\mathrm{LC}_{90}\right)$ with $95 \%$ fiducial limits were calculated in each bioassay to estimate the difference between the test samples. Additional statistical parameters, such as standard error, chi-square and regression coefficient, were also calculated.

\subsection{Effect of Achyranthes aspera Extracts on the Midgut Histo-architecture of Aedes aegypti Larvae}

The histological studies were performed on the larvae exposed to hexane extract of the leaf and stem of $A$. aspera at different concentrations; sub-lethal $\left(\mathrm{LC}_{30}\right)$, median-lethal $\left(\mathrm{LC}_{50}\right)$ and lethal $\left(\mathrm{LC}_{90}\right)$. A total of 20 larvae were exposed to the selected concentrations for $6 \mathrm{~h}, 12 \mathrm{~h}$ and $24 \mathrm{~h}$. Moribund larvae were examined to avoid post-mortem changes. The exposed larvae were fixed in the $10 \%$ formaldehyde for $24 \mathrm{~h}$, dehydrated through a graded series of ethanol, cleared with xylene and embedded in the melted paraffin blocks. The paraffin blocks were sectioned at $3 \mu \mathrm{m}$ thickness using a rotary microtome and stained with haematoxylin and eosin. The sections were examined under a light microscope (Nikon E600) for histological modifications and photographed by a Canon Power Shot Camera (SX50HS). 


\section{RESULTS}

The mortality of early fourth instars of Ae. aegypti when exposed to graded series of hexane extract of the leaf and stem of $A$. aspera for $24 \mathrm{~h}$ are presented in Table 1 and Fig. 1. The lethal concentrations representing 30\%, 50\% and $90 \%$ larval mortality are presented in Table 2 . The data clearly revealed the dose-dependent mortality, the rate of mortality positively correlated with the concentration of both the extracts. Exposure of early fourth instars of $A e$. aegypti with hexane extract of the leaf of $A$. aspera resulted in respective $\mathrm{LC}_{30}, \mathrm{LC}_{50}$ and $\mathrm{LC}_{90}$ values of 67,83 and 140 ppm while larval exposure to hexane extract of the stem showed respective values of 55, 68 and 115 ppm (Table 2). The hexane extract of the stem of $A$. aspera was, thus found 0.82 -fold more efficient against dengue larvae as compared to the hexane extract of the leaf; $\mathrm{LC}_{50}$ value of hexane extract of the leaf found to be 1.21-fold higher than the stem extract. In contrast, no mortality was recorded in case of negative control while $100 \%$ mortality was observed when larvae were exposed to $0.1 \mathrm{ppm}$ of permethrin.

Table 1. Total larval mortality of early fourth instars $(\mathrm{n}=\mathbf{2 0})$ of Aedes aegypti when exposed to hexane extract of the leaf and stem of Achyranthes aspera for $24 \mathrm{~h}$.

\begin{tabular}{|c|c|c|c|c|c|c|c|c|c|c|c|}
\hline \multirow{2}{*}{ Hexane Extract } & \multicolumn{9}{|c|}{$\begin{array}{c}\text { Concentrations } \\
\text { (ppm) }\end{array}$} \\
\cline { 2 - 11 } & $\begin{array}{c}\mathbf{0 . 1} \\
\text { Permethrin }\end{array}$ & $\mathbf{1 0 0 0}$ & $\mathbf{5 0 0}$ & $\mathbf{2 5 0}$ & $\mathbf{1 5 0}$ & $\mathbf{1 0 0}$ & $\mathbf{8 0}$ & $\mathbf{6 0}$ & $\mathbf{4 0}$ & $\mathbf{2 0}$ & $\mathbf{C o n t r o l}$ \\
\hline Leaf Extract & $20 \pm 0.00$ & $20 \pm 0.00$ & $20 \pm 0.00$ & $20 \pm 0.00$ & $16.50 \pm 0.64$ & $15.50 \pm 0.28$ & $7.50 \pm 0.28$ & $4.00 \pm 0.50$ & $0.50 \pm 0.28$ & $0.0 \pm 0.0$ & $0.0 \pm 0.0$ \\
\hline Stem Extract & $20 \pm 0.00$ & $20 \pm 0.00$ & $20 \pm 0.00$ & $20 \pm 0.00$ & $20 \pm 0.00$ & $19.50 \pm 0.28$ & $7.50 \pm 0.28$ & $5.00 \pm 0.40$ & $4.50 \pm 0.28$ & $0.0 \pm 0.0$ & $0.0 \pm 0.0$ \\
\hline
\end{tabular}

Total larval mortality \pm SEM, Values are mean of three replicates.

Table 2. Lethal concentrations of hexane extract of the leaf and stem of Achyranthes aspera against early fourth instars of Aedes aegypti at different mortality levels calculated by regression analysis using computerized statistical program SPSS (Version 19.0).

\begin{tabular}{|c|c|c|c|c|c|c|c|}
\hline \multirow{2}{*}{ Extract } & \multicolumn{5}{|c|}{ Lethal Concentration (ppm) } \\
\cline { 2 - 7 } & $\mathbf{L C}_{\mathbf{3 0}}$ & $\mathbf{L C}_{\mathbf{5 0}}$ & $\mathbf{L C}_{\mathbf{9 0}}$ & R.C. & $\chi^{\mathbf{2}}$ & S.E. & df \\
\hline Hexane Extract of Leaf & $\begin{array}{c}67 \\
(56.45-74.56)\end{array}$ & $\begin{array}{c}83 \\
(73.55-91.86)\end{array}$ & $\begin{array}{c}140 \\
(120.89-177.65)\end{array}$ & 5.6 & 6.7 & 0.8 & 6 \\
\hline Hexane Extract of Stem & $\begin{array}{c}55 \\
(21.80-70.98)\end{array}$ & $\begin{array}{c}68 \\
(42.34-92.72)\end{array}$ & $(86.68-440.53)$ & 5.6 & 15.9 & 0.9 & 5 \\
\hline
\end{tabular}

$\mathrm{LC}_{30}$ - Lethal Concentration that kills $30 \%$ of the exposed larvae, $\mathrm{LC}_{50}$ - Lethal Concentration that kills $50 \%$ of the exposed larvae, $\mathrm{LC}_{90}-\mathrm{Lethal}$ Concentration that kills $90 \%$ of the exposed larvae; Values are mean of three replicates; Values in parentheses indicate the lower and upper $95 \%$ fiducial limits; R.C. $=$ Regression Coefficient, $\chi^{2}=$ Chi-square, S.E. $=$ Standard Error, $\mathrm{df}=$ degree of freedom, Test samples were transformed into log covariant $(\log 10), p>0.05$, level of significance is greater than 0.05 , no heterogeneity factor is used in the calculation of confidence limits.

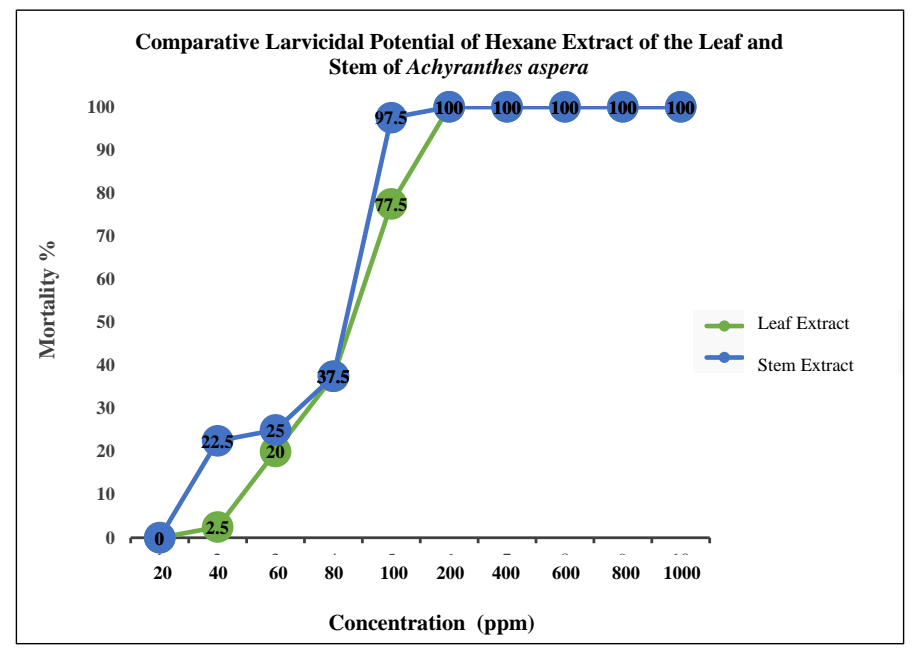

Fig. (1). Comparative percent mortality of early fourth instars of Aedes aegypti on exposure to different concentrations of hexane extract of the leaf and stem of Achyranthes aspera. 
Investigations on the efficacy of $A$. aspera extracts as a stomach poison against Ae. aegypti larvae and their impact on the midgut architecture of early fourth instar larvae of Ae. aegypti were conducted by exposing larvae at three levels of lethal concentrations; $\mathrm{LC}_{30}, \mathrm{LC}_{50}$ and $\mathrm{LC}_{90}$; of hexane extracts of the leaf and stem. Periodic observations were made at a different exposure time of $6 \mathrm{~h}, 12 \mathrm{~h}$ and $24 \mathrm{~h}$. The results showed that the stem extract, which was found more toxic to the larval survival, was also observed to impart more deleterious effects on larval midgut histoarchitecture in contrast to the leaf extract.

Histological observations showed that the midgut of the early fourth instar of Ae. aegypti in negative control assays (exposed to ethanol alone) (Fig. 2a) was composed of single-layered epithelium consisting of two distinguishable cell types; columnar (or digestive) cells and regenerative cells resting on a basement membrane. The spherical nuclei; containing prominent decondensed chromatin and a nucleolus; were located basally. The peritrophic membrane surrounding the lumen was regular and smoothly attached to the epithelium. While, in case of positive control (exposed to permethrin), complete destruction of midgut epithelial layer was observed after $24 \mathrm{~h}$ of exposure (Fig. 2b).

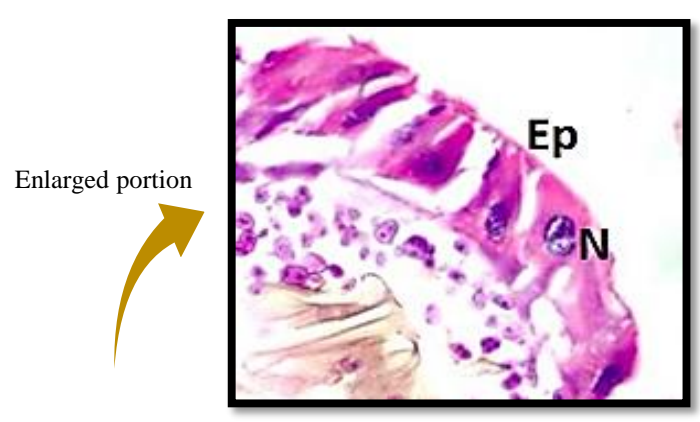

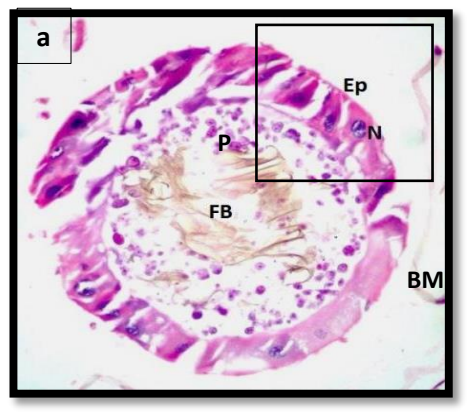

$(6 \mathrm{~h})$

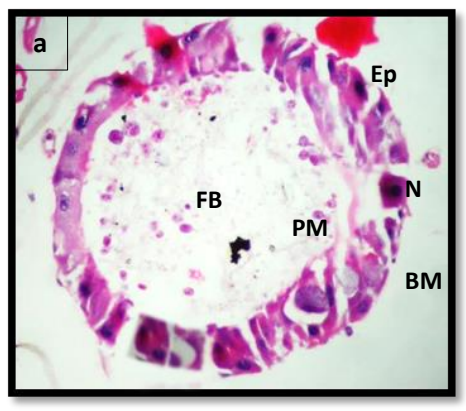

(12 h)

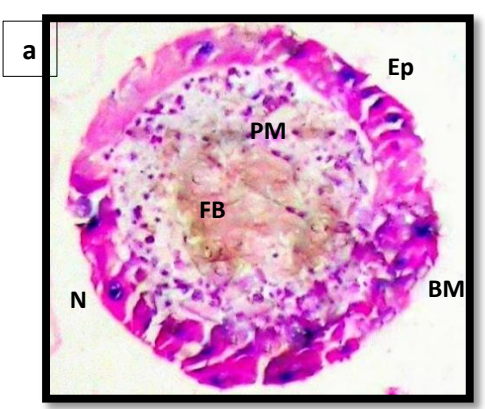

$(24 \mathrm{~h})$

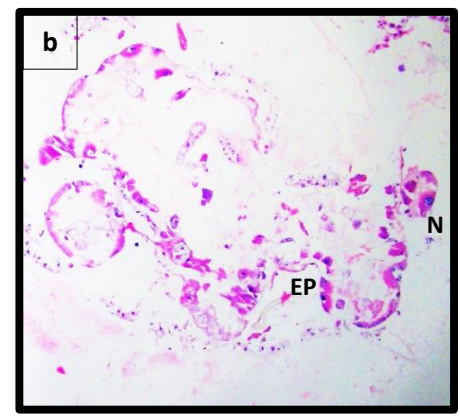

Fig. (2). Photomicrographs of T.S. of midgut epithelium of early fourth instars of Aedes aegypti. a) Exposed to negative control (ethanol alone) in control experiment; b) Exposed to positive control (permethrin); Epithelial cells (Ep), Nucleus (N), Food bolus (FB), Peritrophic Membrane (PM), and Basement Membrane (BM) * Magnification: 40X

The histological studies showed conspicuous morphological aberrations in the extract-exposed larvae as compared to control and the extent of midgut damage was dose-dependent. Also, the exposure to Ae. aegypti larvae to A. aspera hexane extract of the stem led to more damaging effects as compared to the exposure to leaf extract (Figs. 3-5). 


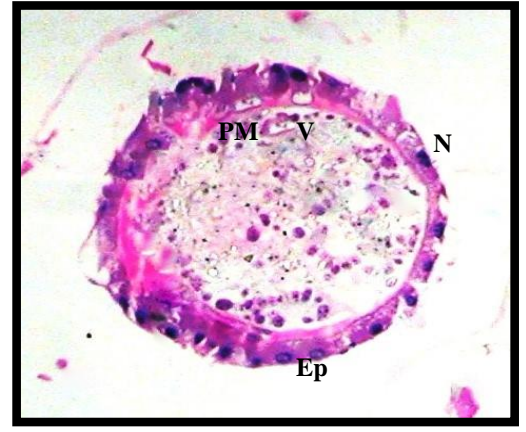

(6 h)

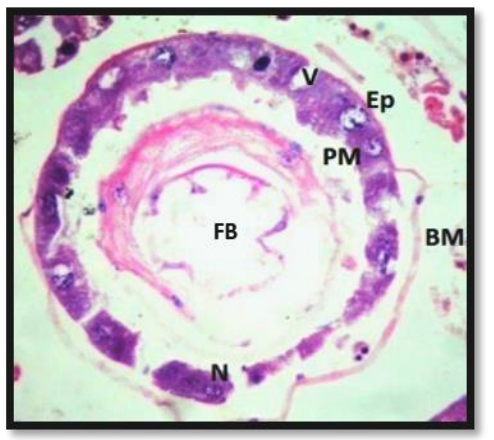

(12 h)

\section{LC $_{30}$ of Leaf Extract}

$(12 \mathrm{~h})$

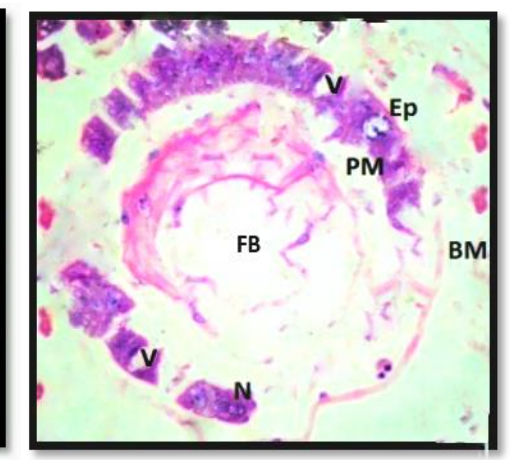

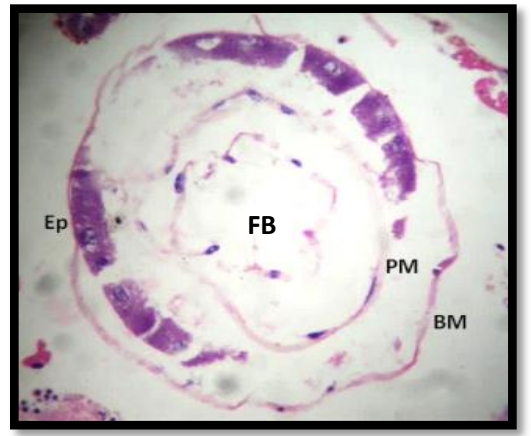

$(24 \mathrm{~h})$

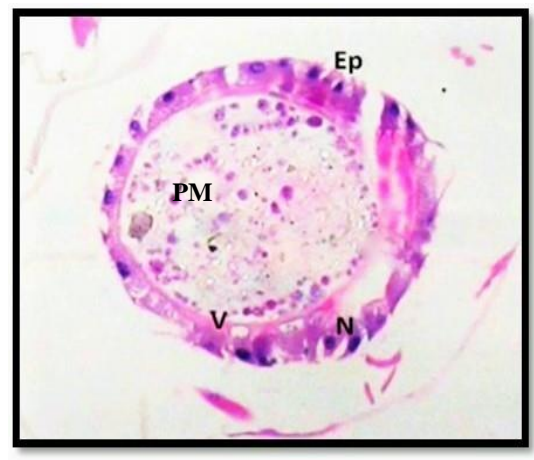

(6 h)

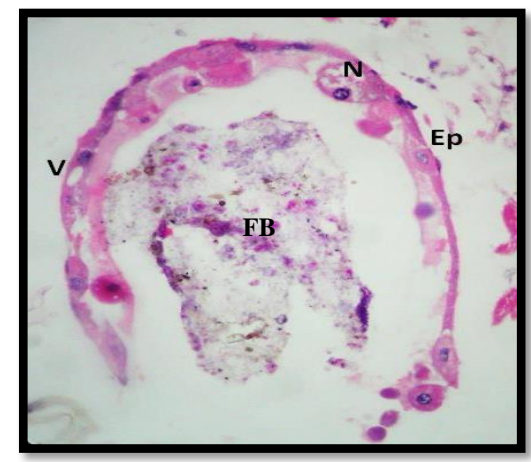

$(24 \mathrm{~h})$

\section{$\mathbf{L C}_{\mathbf{3 0}}$ of Stem Extract}

Fig. (3). Photomicrographs of T.S. of midgut epithelium of early fourth instars of Aedes aegypti exposed to hexane extract of leaf and stem of Achyranthes aspera at $\mathrm{LC}_{30}$; Epithelial cells (Ep), Peritrophic Membrane (PM), Nucleus (N), Vacuole (V), and Basement Membrane (BM) * Magnification: 40X.

The larval exposure to $A$. aspera extracts at $\mathrm{LC}_{30}$ level induced lysis of midgut epithelium layer, vacuolization and partial destruction of the peritrophic membrane and cytoplasmic organelles at $6 \mathrm{~h}$ whereas no vacuole was observed in the control case, epithelium layer was intact and normal. Basement membrane was displaced a little from epithelial layer. The peritrophic membrane was damaged and broken at several places leading to oozing out of food contents (Fig. 3). Increase in the exposure duration caused the amplified degeneration of the midgut structure of early fourth instars of Ae. aegypti. Almost half of the midgut epithelial cells degenerated completely. The peritrophic and basement membrane were dislocated completely. Negligible traces of ruptured epithelial cells signified comprehensive deterioration of entire midgut structure.

The larval exposure to $\mathrm{LC}_{50}$ and $\mathrm{LC}_{90}$ dosages of hexane extract of the leaf and stem of $A$. aspera showed more prominent and marked alterations in the midgut architecture (Figs. 4, 5) of Ae. aegypti larvae when compared to the damage caused at sub-lethal dosage. The midgut structure was comprehensively and severely damaged. The epithelial cells atrophied completely, vacuolization was more distinct and the peritrophic membrane broke at several places with the muscles tissue ragged completely leading to their detachment from basement membrane. As the exposure duration increased, the larvae experienced a similar extent of damage caused by permethrin (positive control) (Fig. 2b) with a high rate of vacuolization with complete degeneration of gut epithelial tissue. Disrupted and disintegrated epithelial cells were found to be scattered all over the midgut architecture with indistinct luminal contents and cellular structure of midgut (Fig. 5). 


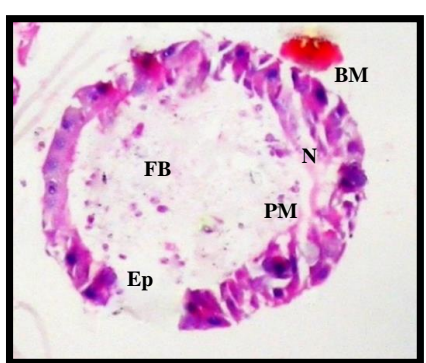

$(6 \mathrm{~h})$

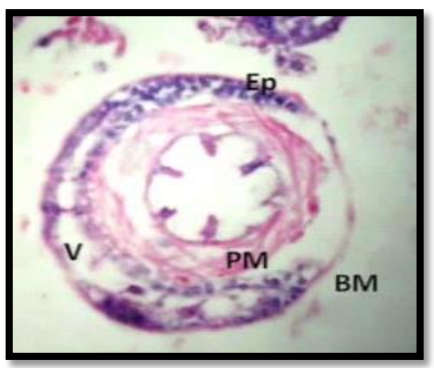

$(6 \mathrm{~h})$

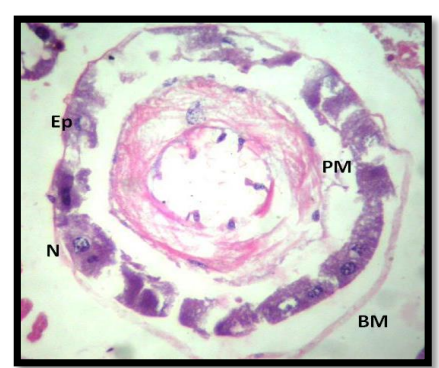

$(12 \mathrm{~h})$

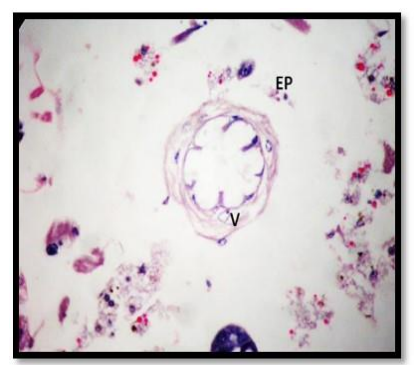

$(24 \mathrm{~h})$

\section{$\mathbf{L C}_{\mathbf{5 0}}$ [of $\square /$ HDIExtract}

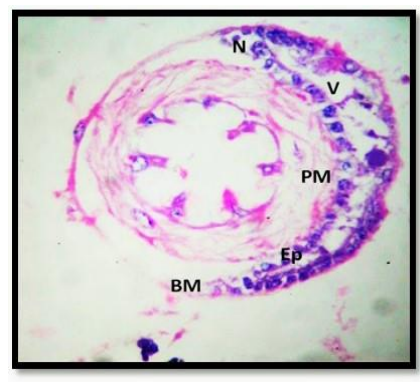

$(12 \mathrm{~h})$

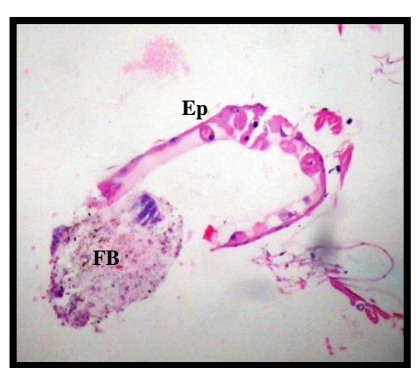

$(24 \mathrm{~h})$

\section{$\mathbf{L C}_{\mathbf{5 0}}$ of Stem Extract}

Fig. (4). Photomicrographs of T.S. of midgut epithelium of early fourth instars of Aedes aegypti exposed to hexane extract of leaf and stem of Achyranthes aspera at $\mathrm{LC}_{50}$; Epithelial cells (Ep), Peritrophic Membrane (PM), Nucleus (N), Vacuole (V), and Basement Membrane $(\mathrm{BM}) *$ Magnification: $40 \mathrm{X}$.

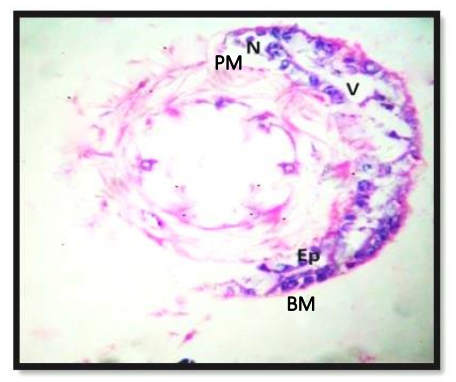

$(6 \mathrm{~h})$

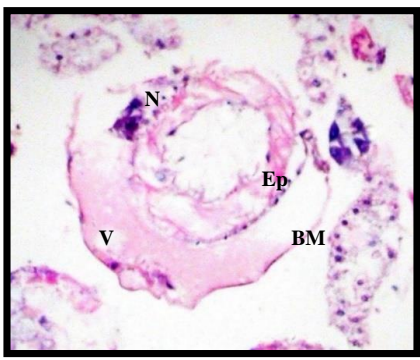

$(6 \mathrm{~h})$

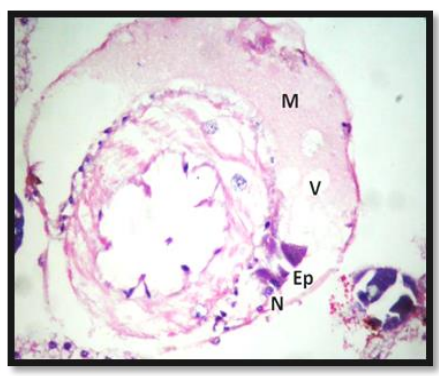

(12 h)

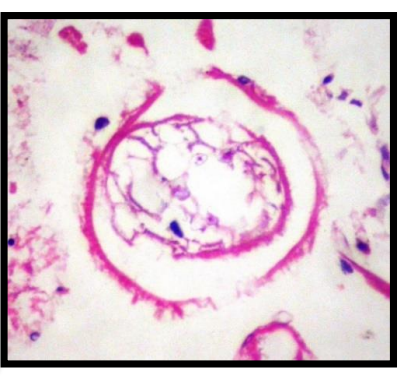

$(24 \mathrm{~h})$

\section{LC90 of Leaf extract}

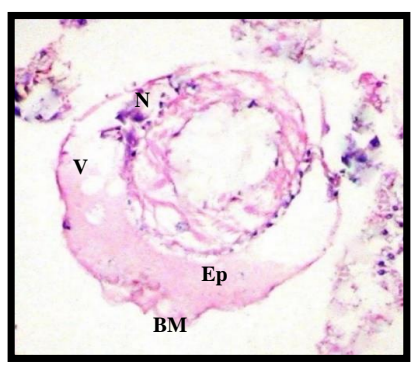

(12 h)

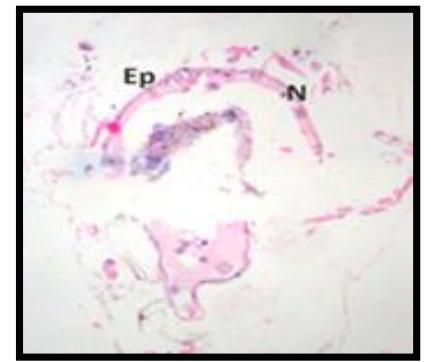

(24 h)

LC90 of Stem extract

Fig. (5). Photomicrographs of T.S. of midgut epithelium of early fourth instars of Aedes aegypti exposed to hexane extract of leaf and stem of Achyranthes aspera at $\mathrm{LC}_{90}$; Epithelial cells (Ep), Peritrophic Membrane (PM), Nucleus (N), Vacuole (V), Muscle (M) and Basement Membrane (BM) * Magnification: 40X. 


\section{DISCUSSION}

The mosquito control at the larval stage of development with phytochemicals using several plant parts, i.e., fruit, flower, leaf, stem and root is one of the cost-effective, easy to use, and environment-friendly method. Over 2000 plants species have been known to produce such chemicals and metabolites exhibiting high value in pest control programs, and products of about 344 species among these plants have been reported to own a variety of activities and potentials against mosquitoes $[19,20]$. It has been proved that the utilization of crude or partially purified plant extracts against mosquitoes are very effective and involve a lesser cost in comparison with purified compounds or extracts [21 - 23]. Since, plant extracts are frequently active against specific target insects and possibly appropriate for use in mosquito control programme, they could lead to the formulation of new classes of insect control agents that would be possible safer [24].

The present study showed the varied larvicidal activities of the hexane extract of the leaf and stem of $A$. aspera against $A$ e. aegypti, the stem extract exhibited higher larvicidal potential as compared to the leaf extract. These results are in accordance with the findings of Khandagle et al. [25] who also reported the 0.81 -fold higher efficacy of stems as compared to leaves of $A$. aspera against Ae. aegypti. They evaluated the larvicidal potential of essential oils extracted from leaves and stems of $A$. aspera against $C x$. quinquefasciatus and the $\mathrm{LC}_{50}$ values reported by them were (Stem extract - 668 ppm; Leaf extract - $761 \mathrm{ppm}$ ) much higher than obtained in present studies. Likewise, Kumar et al. [26] revealed the appreciable larvicidal potential of hexane extract prepared from $A$. aspera stems against Ae. aegypti with $\mathrm{LC}_{50}=58 \mathrm{ppm}$. Bagavan et al. [27] reported the bio-efficacy of leaves, flowers and the seeds extract prepared from $A$. aspera against the fourth instars of An. subpictus and $C x$. tritaeniorhynchus whereas the saponins isolated from the ethyl acetate extract of $A$. aspera leaves were found as potential larvicides against Ae. aegypti and Cx. quinquefasciatus. Similarly, acetone leaf extracts of $A$. aspera assayed against different instars of $C x$. vishnui revealed $\mathrm{LC}_{50}$ values ranging from $35.46 \mathrm{ppm}$ to $63.39 \mathrm{ppm}$, the value decreasing with the increase in the time of exposure [28].

The midgut of the mosquito larva is the organism's interface with the external environment and performs the function of digestion, absorption, ion transport, and osmoregulation [29]. Previous investigations have identified the midgut region of the larvae as the primary site of cellular responses to any toxicant [30]. Ray et al. [31] had also established that plant extract and their isolated compounds mainly affect the midgut epithelium. The studies have suggested that the larvicidal substances present in the plant extracts can damage epithelial cells of the midgut, the sites of digestion and absorption of substances. Irrespective of the type of toxicant used, the comparison of the induced detrimental changes in the organism designates that these alterations are a common response to cellular intoxication [32]. It is suggested that the larvicides may cross passively or disrupt the PM structure, which adversely affects the insect midgut architecture. Disintegration of columnar cells and cytoplasmic vacuolization observed to be a common response of Ae. aegypti to toxicants. It is suggested to be due to an osmotic imbalance via impairment of ion channels which further builds up pressure and causes cell lysis leading to luminal-directed casting off of cell portions involved in the apocrine secretion of digestive enzymes, the renewal or apoptosis processes [33].

The present study also showed distinct histopathological alterations in the midgut of Ae. aegypti early fourth instars when exposed to $A$. aspera stem and leaf extracts. These adversities include enlarged intercellular spaces, increased cytoplasmic vacuolization, deformed or destructed epithelial layer and disintegrated nuclei and nucleoli. Moreover, alteration of microvilli and detachment of peritrophic membrane led to the complete destruction of midgut architecture. These histopathological effects of the hexane extract of leaf and stem of $A$. aspera on the midgut architecture of Ae. aegypti were in agreement with the earlier reports of Gusmão et al. [11], Pavananundt et al. [32], Costa et al. [10], Abed et al. [34], Ndione et al. [35] who also observed similar changes in mosquito larvae on exposure to different plant extracts. Hamouda et al. [36] observed vacuolated epithelial layer, enflamed cells, the presence of cellular material masses in the lumen leading to loss of normal appearance of the midgut epithelium of Cx. pipiens larvae after exposure to Artemisia judaica extract. They also found that larvae treated with Anagallis arvensis showed ruptured cell wall and marked destruction of the peritrophic membrane. Lethal disruption of the peritrophic membrane, cell disintegration and separation of basal membranes was reported by Gusmão et al. [11] on the treatment of Ae. aegypti larvae with an aqueous suspension of ethanol extract of D. urucu. Costa et al. [10] studied morphological changes in the midgut of $A e$. aegypti larvae following treatment with a methanolic extract of $A$. coriacea and observed enlargement of apical surfaces, cytoplasmic vacuolization, luminal-directed elimination of portions of the apical cytoplasm from columnar midgut cells. 
Extracts of Copaifer reticulata caused the total or partial destruction of midgut epithelial cells, vacuolization of cytoplasm, complete damage to the peritrophic matrix [34] of Ae. aegypti larvae. The midgut columnar cells of Ae. aegypti responded with intense cytoplasmic vacuolization following treatment with $M$. pubescens extracts [37] and with S. saponaria [38]. The histopathological effects of neem products on the larvae of Ae. aegypti showed serious damages of the columnar epithelial cells, perturbation of alimentary flow in the alimentary canal, slight hypertrophy of some cells, vacuolization degeneration and extensive lysis of some cells [35]. Kaewnang-O et al. [39] tested the impact of fixed oil and crude extract from sa-dao-thiam, Azadirachta excels (Jack) seed kernel against Ae. aegypti and observed damaged midgut epithelial cells, noted hypertrophy and degeneration of the epithelial cells ensuing in existence of some cytoplasmic material in the alimentary canal. The midgut epithelial cells of Ae. aegypti responded with intense cell vacuolization, rupture of epithelial walls, microvillus damage, leakage or passing of cell contents into the lumen following treatment with a Melia azedarach extract [23] and Matricharia chamomella extracts [40] against Cx. quinquefasciatus. Histological studies of Cassia siamea leaf aqueous extract against Ae. aegypti larvae showed partial damage to epithelial cells through local detachment from the basal membrane, degeneration of microvilli and appearance of several vesicles and cytoplasm masses [32]. Similar histopathological alterations were reported by Jiraungkoorskul et al. [41] against Cx. quinquefasciatus larvae and lesions, swelling, and deformation or elongation of the midgut epithelial cells were recorded on exposure to aqueous leaf extract of $C$. siamea. Elumalai et al. [42] isolated catechin from the Leucas aspera, evaluated its histopathological effects on the fourth-instar larvae of Ae. aegypti, An. stephensi and $C x$. quinquefasciatus and observed the midgut epithelial layer as the main site affected intensely. Moreover, they noticed disarrangement, swelling, and distinct protrusion of columnar cells into the gut lumen, separation of epithelial cells from the basement membrane, vacuolization and nuclei of enlargement gut cells.

\section{CONCLUSION}

The results of our investigation revealed the toxic potential of $A$. aspera leaf and stem extracts against early fourth instars of Ae. aegypti. The potential of extract was found to be increasing with increasing concentration and time of exposure, hexane extract of stem exhibiting higher potential in comparison to the leaf extract. The hexane leaf and stem extract also imposed deleterious effect on the gut-histoarchitecture leading to death of the exposed larvae. The extracts, thus demonstrated its stomach poison properties against Ae. aegypti larvae. Being natural in origin, easily biodegradable to non-toxic byproducts and cost-effective, the use of A. aspera can be recommended as a promising botanical insecticide in the fields to control the dengue vector. However, further researches are needed to investigate the plant against non-target population and other mosquito species to establish its effective use in in the mosquito control program. Identification and isolation of bioactive phytoconstituent will be useful to devise control strategies.

\section{ETHICS APPROVAL AND CONSENT TO PARTICIPATE}

Not applicable.

\section{HUMAN AND ANIMAL RIGHTS}

No animals/humans were used for studies that are the basis of this research.

\section{CONSENT FOR PUBLICATION}

Not applicable.

\section{CONFLICT OF INTEREST}

The authors declare no conflict of interest, financial or otherwise.

\section{ACKNOWLEDGEMENTS}

Aarti Sharma conceived the idea and conducted the experiments. Aarti Sharma and Pushplata Tripathi designed the experiments and sourced for funds. Pushplata Tripathi and Sarita Kumar supervised and guided the experiments. Aarti Sharma and Sarita Kumar recorded the microscopic observations and Sarita Kumar helped in the analysis of the results. All the authors were involved in the preparation of the manuscript. Authors are highly grateful to Dr. Savithri Singh, Principal, Acharya Narendra Dev College, University of Delhi and School of Sciences, Indira Gandhi National Open University for providing infrastructure and research facilities. 


\section{REFERENCES}

[1] WHO. Dengue Control. 2015; Accessed on 23 ${ }^{\text {rd }}$ April 2017. Available from: http://www.who.int/denguecontrol/en

[2] National Vector Borne Disease Control Programme (NVBDCP). Clinically suspected chikungunya fever cases since 2010. 2018a; Accessed on 19th January 2018, Available from: http://www.nvbdcp.gov.in/chik-cd.html

[3] National Vector Borne Disease Control Programme (NVBDCP). Dengue cases and deaths in the country since 2010. 2018b; Accessed on 19th January 2018, Available from: http://nvbdcp.gov.in/den-cd.html

[4] World Health Organization. Immunization, vaccines and biologicals. 2016; Accessed on 5th April 2017. Available from: http://www.who.int/immunization/diseases/dengue/en

[5] Malathi P, Vasugi SR. Evaluation of mosquito larvicidal effect of Carica papaya against Aedes aegypti. Int J Mosquito Res 2015; 2 (3): 21-4.

[6] ICMR Bulletin. Prospects of using herbal products in the control of mosquito vectors. 2003; 33: 1-10.

[7] Ghayal N, Padhye A, Dhumal K. Larvicidal activity of invasive weeds Cassia uniflora and Synedrella nodiflora. Int J Pharma Bio Sci 2010; 1(3).

[8] Mandal S. Repellent activity of Eucalyptus and Azadirachta indica seed oil against the filarial mosquito Culex quinquefasciatus Say (Diptera: Culicidae) in India. Asian Pac J Trop Biomed 2011; 1: 109-12. [http://dx.doi.org/10.1016/S2221-1691(11)60135-4]

[9] Procópio TF, Fernandes KM, Pontual EV, et al. Schinus terebinthifolius leaf extract causes midgut damage, interfering with survival and development of Aedes aegypti larvae. PLoS One 2015; 10(5): e0126612. [http://dx.doi.org/10.1371/journal.pone.0126612] [PMID: 25974067]

[10] Costa MS, Pinheiro DO, Serrão JE, Pereira MJB. Morphological changes in the midgut of Aedes aegypti L. (Diptera: Culicidae) larvae following exposure to an Annona coriacea (Magnoliales: Annonaceae) extract. Neotrop Entomol 2012; 41(4): 311-4. [http://dx.doi.org/10.1007/s13744-012-0050-z] [PMID: 23950067]

[11] Gusmão DS, Páscoa V, Mathias L, Curcino Vieira IJ, Braz-Filho R, Alves Lemos FJ. Derris (Lonchocarpus) urucu (Leguminosae) extract modifies the peritrophic matrix structure of Aedes aegypti (Diptera:Culicidae). Mem Inst Oswaldo Cruz 2002; 97(3): $371-5$. [http://dx.doi.org/10.1590/S0074-02762002000300017] [PMID: 12051197]

[12] Al-Mekhlafi FA. Larvicidal, ovicidal activities and histopathological alterations induced by Carum copticum (Apiaceae) extract against Culex pipiens (Diptera: Culicidae). Saudi J Biol Sci 2018; 25(1): 52-6. [http://dx.doi.org/10.1016/j.sjbs.2017.02.010] [PMID: 29379357]

[13] Ray K, Mercedes M, Chan D, Choi CY, Nishiura JT. Growth and differentiation of the larval mosquito midgut. J Insect Sci 2009 ; 9: 1-13. [http://dx.doi.org/10.1673/031.009.5501] [PMID: 20053117]

[14] Fernandes KM, Neves CA, Serrão JE, Martins GF. Aedes aegypti midgut remodeling during metamorphosis. Parasitol Int 2014; 63(3): 506-12. [http://dx.doi.org/10.1016/j.parint.2014.01.004] [PMID: 24472855]

[15] Dey A. Achyranthes aspera L: phytochemical and pharmacological aspects. Int J Pharm Sci Rev Res 2011; 9: 72-82.

[16] Sharma A, Kumar S, Tripathi P. Evaluation of the larvicidal efficacy of five indigenous weeds against an Indian strain of dengue vector, Aedes aegypti L. (Diptera: Culicidae). J Parasitol Res 2016; 2016: 2857089. [http://dx.doi.org/10.1155/2016/2857089] [PMID: 26941996]

[17] Mukandiwa L, Eloff JN, Naidoo V. Larvicidal activity of leaf extracts and seselin from Clausena anisata (Rutaceae) against Aedes aegypti. S Afr J Bot 2015; 100: 169-73.

[http://dx.doi.org/10.1016/j.sajb.2015.05.016]

[18] Report WHO. World Malaria Report. Geneva: WHO/UNICEF 2005.

[19] Sukumar K, Perich MJ, Boobar LR. Botanical derivatives in mosquito control: A review. J Am Mosq Control Assoc 1991; 7(2): 210-37. [PMID: 1680152]

[20] Ghosh A, Chowdhury N, Chandra G. Plant extracts as potential mosquito larvicides. Indian J Med Res 2012; 135(5): 581-98. [PMID: 22771587]

[21] Jang YS, Kim MK, Ahn YJ, Lee HS. Larvicidal activity of Brazilian plants against Aedes aegypti and Culex pipiens pallens (Diptera: Culicidae). J Korean Soc Appl Biol Chem 2002; 45: 131-4.

[22] Cavalcanti ESB, Morais SM, Lima MA, Santana EW. Larvicidal activity of essential oils from Brazilian plants against Aedes aegypti L. Mem Inst Oswaldo Cruz 2004; 99(5): 541-4 [http://dx.doi.org/10.1590/S0074-02762004000500015] [PMID: 15543421]

[23] Al-Mehmadi RM, Al-Khalaf AA. Larvicidal and histological effects of Melia azedarach extract on Culex quinquefasciatus Say larvae (Diptera: Culicidae). J King Saud Univ (Science) 2010; 22: 77-85. [http://dx.doi.org/10.1016/j.jksus.2010.02.004]

[24] Alkofahi A, Rupprecht JK, Anderson JE, Mclaughlin JL, Mikolajczak KL, Scott BA. Search for new pesticides from higher plants Insecticides of plant origin. ACS publications 1989; pp. 25-43. 
[http://dx.doi.org/10.1021/bk-1989-0387.ch003]

[25] Khandagle AJ, Tare VS, Raut KD, Morey RA. Bioactivity of essential oils of Zingiber officinalis and Achyranthes aspera against mosquitoes. Parasitol Res 2011; 109(2): 339-43. [http://dx.doi.org/10.1007/s00436-011-2261-3] [PMID: 21311910]

[26] Kumar S, Wahab N, Mishra M, Warikoo R. Evaluation of 15 local plant species as larvicidal agents against an Indian strain of dengue fever mosquito, Aedes aegypti L. (Diptera: Culicidae). Front Physiol 2012; 23(3):104, 1-6.

[27] Bagavan A, Rahuman AA, Kamaraj C, Geetha K. Larvicidal activity of saponin from Achyranthes aspera against Aedes aegypti and Culex quinquefasciatus (Diptera: Culicidae). Parasitol Res 2008; 103(1): 223-9. [http://dx.doi.org/10.1007/s00436-008-0962-z] [PMID: 18392726]

[28] Bhattacharya K, Chandra G. Bioactivity of Achyranthes aspera (Amaranthaceae) foliage against the Japanese encephalitis vector Culex vishnui Group. J of Mosq Res 2013; 3(13): 89-96.

[29] Bernick EP, Moffett SB, Moffett DF. Organization, ultrastructure, and development of midgut visceral muscle in larval Aedes aegypti. Tissue Cell 2007; 39(4): 277-92. [http://dx.doi.org/10.1016/j.tice.2007.05.003] [PMID: 17675126]

[30] David JP, Rey D, Pautou MP, Meyran JC. Differential toxicity of leaf litter to dipteran larvae of mosquito developmental sites. J Invertebr Pathol 2000; 75(1): 9-18. [http://dx.doi.org/10.1006/jipa.1999.4886] [PMID: 10631052]

[31] Rey D, Cuany A, Pautou M, Meyran J. Differential sensitivity of mosquito taxa to vegetable tannins. J Chem Ecol 1999; 25: 537-48. [http://dx.doi.org/10.1023/A:1020953804114]

[32] Pavananundt P, Jiraungkoorskul K, Kosai P, Jiraungkoorskul W. Larvicidal properties of Cassia siamea leaf against Ae. aegypti larvae. Int J Mod Agric 2013; 2: 1

[33] Lehane MJ, Billingsley PF. Biology of the insect midgut. London: Chapman and Hall 1996; p. 486. [http://dx.doi.org/10.1007/978-94-009-1519-0]

[34] Abed RA, Cavasin GM, Silva HHG, Silva IG. Alterações morfohistológicas em larvas de Aedes aegypti (Linnaeus, 1762) (Diptera, Culicidae) causadas pela atividade larvicida do óleo-resina da planta medicinal Copaifera reticulata Ducke (Leguminosae). Rev Patol Trop 2007; 36 : 87-95.

[35] Ndione RD, Faye O, Ndiaye M, Dieye A, Afoutou JM. Toxic effects of neem products (Azadirachta indica A. Juss) on Aedes aegypti Linnaeus 1762 larvae. Afr J Biotechnol 2007; 6: 2846-54. [http://dx.doi.org/10.5897/AJB2007.000-2454]

[36] Hamouda LS, Elyassaki WM, Hamed MS. Toxicity and histopathological effects of Artemisia judaica and Anagallis arvensis extracts on Culex pipiens larvae. J Basic Appl Zool 1996; 20: 43-60.

[37] Arruda W, Oliveira GM, da Silva IG. Toxicity of the ethanol extract of Magonia pubescens on larvae Aedes aegypti. Rev Soc Bras Med Trop $2003 ; 36(1): 17-25$

[http://dx.doi.org/10.1590/S0037-86822003000100004] [PMID: 12715059]

[38] Barreto CF, Cavasin GM, Silva HHG, Silva IG. Estudos das alterações morfohistológicas em larvas de Aedes aegypti (Diptera, Culicidae) submetidas ao extrato bruto etanólico de Sapindus saponaria Lin (Sapindaceae). Rev Patol Trop 2006; 35: 37-57.

[39] Kaewnang-O E, Ngampongsai A, Subhadhirasakul S, Srichana T. Toxicity of fixed oil and crude extract from sa-dao-thiam, Azadirachta excelsa (Jack) seed kernel to Aedes aegypti (L.). Songklanakarin J Sci Technol 2011; 33: 43-9.

[40] Almehmadi RM. Larvicidal, histopathological and ultra-structure studies of Matricharia chamomella extracts against the rift valley fever mosquito Culex quinquefasciatus (Culicidae: Diptera). J Entomol 2011; 8: 63-72.

[http://dx.doi.org/10.3923/je.2011.63.72]

[41] Jiraungkoorskul K, Jiraungkoorskul W. Larvicidal and histopathological effects of Cassia siamea leaf extract against Culex quinquefasciatus. Trop Life Sci Res 2015; 26(2): 15-25. [PMID: 26868707]

[42] Elumalai D, Hemavathi M, Hemalatha P, Deepaa CV, Kaleena PK. Larvicidal activity of catechin isolated from Leucas aspera against Aedes aegypti, Anopheles stephensi, and Culex quinquefasciatus (Diptera: Culicidae). Parasitol Res 2016; 115(3): $1203-12$. [http://dx.doi.org/10.1007/s00436-015-4856-6] [PMID: 26711450]

(C) 2018 Sharma et al.

This is an open access article distributed under the terms of the Creative Commons Attribution 4.0 International Public License (CC-BY 4.0), a copy of which is available at: https://creativecommons.org/licenses/by/4.0/legalcode. This license permits unrestricted use, distribution, and reproduction in any medium, provided the original author and source are credited. 